\title{
LAS TIC (TECNOLOGÍAS DE LA INFORMACIÓN Y LA COMUNICACIÓN) Y LOS ESTUDIOS BIOGRÁFICOS
}

\author{
José L. Fresquet Febrer \\ Instituto de Historia de la Ciencia y Documentación. Universidad de Valencia-CSIC
}

\section{RESUMEN}

Este trabajo aborda la utilidad de las TIC (tecnologías de la información y la comunicación) para la investigación y difusión de los trabajos de tipo biográfico. Lo hemos dividido en tres partes: a) internet y el trabajo cooperativo para la elaboración de biografías; b) difusión de trabajos biográficos en internet; y c) espacios biográficos en internet.

PALABRAS CLAVE: TIC, tecnologías de la información y comunicación, biografías de científicos y médicos, internet, historia de la medicina.

\section{SUMMARY}

This paper is on usefulness of ICTs (information and communication technologies) for biographical research and its diffusion. Three different parts constitute the body of the paper: (a) internet and co-operative work in elaboration of biographies; (b) internet diffusion of biographical works, where a case study shows possibilities of diffusion and dissemination of biographical materials; and (c) internet biographical sites.

KEY WORDS: ICTs, Information and Communication Technologies, scientific and medical biographies, internet, History of Medicine.

Hace apenas unos años - hasta mediados de los noventa - cualquiera que quisiera investigar o estudiar algún tema relacionado con la historia de la medicina tenía que invertir, generalmente, tiempo y dinero en la localización de fuentes, así como de bibliografía secundaria. En muchos archivos y bibliotecas no se disponía de repertorios, ficheros fiables, catálogos u obras de consulta adecuadas y había que recurrir a los viajes, al encargo de material en fotocopias o microfichas, al préstamo interbibliotecario, etc. La petición de algunos artículos de revista suponía, generalmente, hacer frente a unos costes comparables en ocasiones a los de varias suscripciones anuales a revistas. A 
pesar del esfuerzo realizado, siempre quedaba la posibilidad de que no se hubiera recuperado un documento o texto importante o quedara por consultar algún libro decisivo. Concluido el trabajo, la difusión del mismo en su totalidad no siempre resultaba fácil; recortar, apurar la extensión, seleccionar las imágenes y gráficos o sacrificar el color de estos últimos, son situaciones en las que todos nos hemos encontrado. Peor ha sido acercar nuestros estudios a los no profesionales o seleccionar los medios más adecuados para que llegaran a un público extenso y heterogéneo.

No es necesario insistir mucho en demostrar que la situación ha cambiado radicalmente en pocos años. Los acontecimientos suceden con tal rapidez que no llegamos a darnos cuenta de la revolución que estamos viviendo: la aparición de las TIC (tecnologías de la información y la comunicación) están cambiando nuestros hábitos de trabajo tanto en lo que se refiere a docencia como a investigación. En estos momentos resulta prácticamente imposible acercarse a cualquier tema de investigación sin tener en cuenta las posibilidades que ofrecen las TIC. Completar una referencia bibliográfica casi de forma instantánea, recibir en segundos por correo electrónico el resultado de una búsqueda bibliográfica que se acaba de hacer en un catálogo de una biblioteca situada a centenares de kilómetros de tu lugar de trabajo, obtener una imagen, comprar un artículo o un libro relacionado con el tema, consultar una fuente e imprimirla en papel, se convierte en una realidad de forma rápida y sencilla. Es más, algunos de nuestros repertorios de obligada consulta como el Current Works o la Bibliography of the History of Medicine han desaparecido o se han convertido en versiones consultables a través de internet con interfaces agradables y de uso intuitivo. Las revistas publicadas en papel han comenzado a desaparecer y a ser sustituidas por versiones electrónicas. En resumen, el investigador tiene que ser consciente de la nueva realidad y debe tratar de controlar las herramientas que le permiten acceder a esta información, saber seleccionarla e interpretarla y conocer cómo difundirla y extenderla.

Hemos dividido el trabajo en tres partes: (a) «internet y el trabajo cooperativo» para la elaboración de biografías, donde se indican las posibilidades que ofrecen las TIC para el trabajo cooperativo o en grupo; (b) la «difusión de trabajos biográficos en internet», donde analizamos, a partir de un caso, las posibilidades de difusión y divulgación de materiales biográficos; y (c) «espacios biográficos en internet», que recoge y analiza los sitios web que contienen información de tipo biográfico. 


\section{INTERNET Y EL TRABAJO COOPERATIVO PARA LA ELABORACIÓN DE BIOGRAFÍAS}

Hemos comentado alguna de las ventajas que comportan las nuevas tecnologías de la información y comunicación. Otras, en cambio, no están tan extendidas. Entre éstas podemos mencionar las que facilitan el trabajo cooperativo. Existen valiosas herramientas para grupos que desarrollan un mismo proyecto, sea empresarial, de investigación, o de otro tipo. Son de gran utilidad cuando los miembros del equipo se encuentran físicamente en lugares distintos.

En la gestión de proyectos es tan importante generar un buen soporte documental como poder acceder a él con facilidad. Existen varios sistemas que nos permiten que todos los implicados en un proyecto puedan acceder a la documentación desde cualquier lugar y en cualquier momento. Estos sistemas no están reñidos con otros más clásicos como el correo, el teléfono, las reuniones u otros parecidos; sencillamente son distintos. Entre los principales podemos mencionar los project sites y los groupwares.

Project sites son espacios disponibles en red de acceso restringido sobre un proyecto determinado. Contienen toda la información y documentación sobre el mismo que es compartida por todos los miembros del equipo. Se suelen proteger con contraseña. El contenido se suele estructurar en: información de tipo general (descripción del proyecto, memoria, propuestas de modificación, matriz de responsabilidades), planificación (diagramas, calendarios, reuniones, descripción de actividades, diario de actividades), actas de las reuniones, esquemas, bases de datos, informes de avance, etc ${ }^{1}$.

Los groupwares son otro sistema de gestión compartida de documentación. Son aplicaciones que facilitan la gestión del conocimiento de un grupo de trabajo en un proyecto. Existe una gran variedad, pero todos suelen ofrecer los siguientes servicios: E-mail (web-mail, no POP3), espacio para documentación compartida, espacio de foros, mensajería instantánea, agenda, salas de chat, videoconferencia, pizarra virtual (para hacer esbozos a tiempo real), asignación y recepción de tareas, workflow (diagrama de flujo de trabajo), entre otros. Los groupwares pueden funcionar por intranet o por extranet. En el segundo caso es fundamental tener en cuenta el tema de la seguridad ${ }^{2}$.

1 Por ejemplo, OnProject (http://www.onproject.com/)

2 Por ejemplo Phpgroupware (http://www.phpgroupware.org/) que es un Groove (http://www.groove.net/home/index.cfm), programa que se descarga y se instala en el disco 
Buena parte de estas herramientas se están utilizando en el mundo empresarial y han demostrado ampliamente su utilidad. Lo mismo podemos decir de algunos programas o aplicaciones, como Microsoft Project o MindJet, que pueden llegar a ser ayudas imprescindibles en la planificación de proyectos, en el manejo de información, en la detección de los momentos críticos, en la asociación de ideas, etc. Aunque este tipo de herramientas se están usando fuera de los ámbitos académicos, pueden resultar de gran utilidad en proyectos de carácter institucional, ya sean de investigación, docentes o de difusión del conocimiento.

\section{LA DIFUSIÓN DE TRABAJOS BIOGRÁFICOS EN INTERNET}

Internet es, quizás, el mejor medio para difundir cualquier tipo de trabajos $\mathrm{y}$, entre estos, los de tipo biográfico. Correo electrónico, grupos de noticias, foros, world wide web, anillos de información o rings, bitácoras, weblogs o $b \log s$, etc. Son posibilidades con un gran potencial. La más importante es quizás, el worl wide web. Si se ofrece sin restricciones y el leguaje html se acompaña de las metatags para una adecuada indización por parte de los buscadores, cualquiera que disponga de los medios necesarios puede encontrar y utilizar la información que hemos depositado en un servidor en red.

Hay que tener en cuenta, sin embargo, que el acceso a estos productos tecnológicos es desigual tanto entre los distintos países como dentro de los mismos. Factores socioeconómicos, demográficos y culturales afectan al acceso y uso de la información en la red. Los grupos con menos posibilidades son las minorías, los pobres, las mujeres, los ancianos y los países en desarrollo. Sin embargo, algunos autores, como Michaelson ${ }^{3}$, han descrito redes de comunicación que conectan a gente sin hogar que utiliza los ordenadores de lugares públicos como bibliotecas y a gente de clase media que usa los ordenadores en sus casas, lugares de trabajo o instituciones académicas.

Es difícil saber en la actualidad qué demanda puede tener la información biográfica a través de internet. Con la finalidad de hacernos una idea hemos recurrido a estudiar las visitas a la sección «Epónimos y biografías médicas» de nuestro sitio web http://www.historiadelamedicina.org. Los contenidos de este site se encuentran en Yahoo Web Hosting, en los Estados Unidos de A-

duro y que funciona con tecnología P2P (peer to peer); Twiki (http://www.twiki.org/) es un programa de código abierto. Permite personalizar si se dispone de un programador.

3 MicAelson, K. (1996). 
mérica. El origen de «Historiadelamedicina» fue una página que se integraba en una de las primeras comunidades virtuales que existió, Geocities. Nació en enero de1995, creada por David Bohnett como Beverly Hills Internet (BHI), una forma de proyectar Hollywood al resto del mundo. En dos años se convirtió en una comunidad virtual con sus calles, plazas, barrios temáticos, comunidades de vecinos, etc 4 . Si disponías de un ordenador conectado a la red podías «alquilar» de forma gratuita un «hogar», es decir, un espacio, y «colgar» la información que te pareciera pertinente. La comunidad contaba con un sistema de ayudas y asesoramiento que conseguías de los vecinos más veteranos y de las asociaciones de líderes en un tema determinado. El diseño de las interface basada en la metáfora de una ciudad real, con sus barrios, calles y plazas, se convirtió pronto en un éxito. De 10.000 «hogares» o sitios web en 1995, se pasó a 300.000 antes del comienzo de 1997, y a 520.000 en abril del mismo año. Por entonces varias empresas se habían interesado en el proyecto y colaboraron aportando financiación. Poco después se añadió publicidad en las páginas, sistemas de intercambio de banners, etc, lo que fue muy criticado por los usuarios. Sin embargo, siguió creciendo y, antes de enero de 1998, ya había 1.000.000 de sitios web alojados. En mayo de 1999 Yahoo comenzó a integrar Geocities con 4,5 millones de sitios y en julio del mismo año suprimió la comunidad virtual concebida como una ciudad, aunque continuó ofreciendo servicios gratuitos de alojamiento junto con los de pago hasta hoy.

«Historiadelamedicina» nació en 1996 como una página modesta que ofrecía una selección de enlaces a otras páginas o sitios web relacionados con la historia de la medicina. Una de las secciones que se incorporó en 1999 fue la dedicada a «Epónimos y biografías médicas». Ésta incluye hoy cerca del centenar de voces que se van incrementando de forma periódica. El estudio de las biografías, fechas de inserción y número de visitas que han recibido según las estadísticas del sitio que proporciona Yahoo desde que se registró «historiadelamedicina.org», como dominio, en 2001 ha mostrado lo siguiente. El total de biografías han sido visitadas 144.131 veces hasta noviembre de 2004. Las diez más consultadas han sido la de F. Teodor Schwann (8.937), Luigi Galvani (8.120), Rudolf Virchow (7.685), Camilo Golgi (6.880), Wilhelm C. Rötgen (5.418), Hans A. Krebs (4.918), Gabrielle Falopio (4.701), Harvey W. Cushing (3.930), Marcelo Malpighi ((3.837), y Joseph Lister (3503). De las pocas reflexiones que se pueden hacer es que pocas publicaciones impresas podrían alcanzar este grado de consulta teniendo en cuenta que están redactadas en castellano.

4 Véase: A Geocities History (http://www.geocities.com/dunric/geohist.html) y Geocities, en: Encyclopedia, Sciences Daily (http://www.sciencedaily.com/encyclopedia/geocities). 
La procedencia de esas visitas por países es la siguiente: México con el 27,6 $\%$; España, con el 18,5\%; Argentina, con el 7,8\%; Colombia, con el 6,6\%; Estados Unidos, con el 6,6\%; Perú, con el 6,5\%; Venezuela, con el 4,7\%; Chile, con el 4,3\%; República Dominicana, con el 2,7\%; Bolivia, con el 2\%; Resto, el 7,9\% y de origen desconocido, el 3,6\%. Es evidente que el público procede del mundo de lengua española, incluyendo la extensa comunidad hispana de los Estados Unidos.

Si tomamos la página dedicada a Teodor Schwann, la mayor parte de usuarios han llegado a la biografía a través del buscador google, en menor medida a partir de yahoo y de msn. Un tercio llegó a la página a partir de http://www.google.com.mx/search . Los términos de búsqueda introducidos por el usuario han sido: «theodor Schwann», (51,27\%), «schwann $(20,67 \%)$, «schleiden-schwann» $(12,43 \%)$, «quien es schleiden y schwann « $(7,21 \%)$, «teoria celular de schwann « $(1,35 \%)$. Otra forma de acceder a la página es a través de la página index o principal; esto sucede a partir de la segunda visita y en los casos que revisan de vez en cuando las actualizaciones que han tenido lugar en el sitio. Los días de la semana de mayor actividad son los días laborables, especialmente miércoles y jueves. Las consultas durante los sábados, domingos y festivos de carácter internacional disminuyen de forma notable. En cuanto a los periodos de más actividad, la página que contiene la biografía de Teodor Schwann ha registrado la mayor parte de visitas en septiembre de 2003 (722 veces) y septiembre de 2004 (1020).

Desde septiembre de 2004 estamos realizando mediciones más finas mediante software adecuado (WebLogExpert) que nos proporciona información muy precisa y detallada de lo que sucede en el sitio web a lo largo de la semana. Esta información es muy valiosa, entre otras cosas, para planificar los contenidos del sitio. En la tabla 1, por ejemplo, podemos apreciar las cincuenta biografías más consultadas a lo largo de la semana del 8 al 15 de noviembre de 2004, con detalle de los hits (accesos o peticiones de ficheros de una pàgina), número de visitas, $\mathrm{y}$ número de entradas a esa pàgina de forma directa (por ejemplo, desde un buscador). 
TABLA 1. Los 50 epónimos más consultados durante la semana del 8 al 15 de noviembre de 2004 con detalle de los hits, número de visitantes y como página consultada directamente sin pasar por otro directorio del sitio web.

$\begin{array}{llrrr} & \text { PÁGINA } & \text { HITS } & \text { VISITANTES } & \begin{array}{r}\text { ENTRADA DIRECTA } \\ \text { A LA PÁGINA }\end{array} \\ 4 & \text { Virchow } & 182 & 165 & 152 \\ 5 & \text { Schwann } & 159 & 149 & 132 \\ 7 & \text { Galvani } & 148 & 137 & 133 \\ 12 & \text { Golgi } & 97 & 88 & 83 \\ 15 & \text { Falopio } & 74 & 72 & 64 \\ 17 & \text { Malphigi } & 71 & 69 & 63 \\ 18 & \text { Cushing } & 72 & 68 & 57 \\ 22 & \text { Krebs } & 65 & 65 & 59 \\ 26 & \text { Banting } & 64 & 57 & 50 \\ 27 & \text { Roentgen } & 61 & 56 & 52 \\ 28 & \text { Yersin } & 63 & 56 & 50 \\ 30 & \text { Billroth } & 54 & 47 & 40 \\ 31 & \text { Huntington } & 47 & 47 & 43 \\ 32 & \text { Ricketts } & 48 & 46 & 39 \\ 33 & \text { Langerhans } & 47 & 46 & 42 \\ 36 & \text { Morgagni } & 49 & 45 & 35 \\ 37 & \text { Doppler } & 45 & 45 & 42 \\ 38 & \text { Shiga } & 43 & 43 & 38 \\ 39 & \text { Addison } & 43 & 43 & 29 \\ 40 & \text { Widal } & 45 & 41 & 36 \\ 41 & \text { Babinski } & 44 & 40 & 32 \\ 43 & \text { Vesalio } & 41 & 39 & 34 \\ 44 & \text { Whipple } & 40 & 39 & 33 \\ 46 & \text { Trousseau } & 38 & 38 & 30 \\ 47 & \text { Adler } & 43 & 37 & 27 \\ 49 & \text { Purkinje } & 37 & 35 & 35 \\ 50 & \text { Halsted } & 39 & 34 & 31 \\ & \text { Totales } & \mathbf{1 7 5 9} & \mathbf{1 6 4 7} & \mathbf{1 4 6 1}\end{array}$

Hemos señalado que la mayor parte del público ha llegado directamente a la biografía través de un buscador. Los buscadores más utilizados han sido, en 
este orden, Google, Yahoo, Altavista, MSN, AOL Search, AllTheWeb, Netscape, Search.com y HotBot. En la tabla 3 se reflejan los términos de búsqueda que el usuario ha introducido en google y le han conducido a la página web correspondiente de «historiadelamedicina.org» (semana del 8 al 15 de noviembre de 2004). Como se observa, una buena parte de las veces se introduce el nombre completo o incompleto, y otras, el epónimo. Es fundamental incluir las metatags o etiquetas relativas al título, contenido, palabras clave, etc. en la cabecera del documento html, - que son invisibles para el usuario-, para que los robots puedan indizar el contenido de la página.

TABLA 2. Términos utilizados para las búsquedas que han permitido llegar a las páginas biográficas correspondientes a la semana del 8 al 15 de noviembre de 2004. Sólo se han tomado los datos de Google

\section{FRASE}

Rudolf virchow
Luigi Galvani
Glomerulo
Trompas de Falopio
Corea de Huntington
Joseph Lister
Rickettsias
Camilo Golgi
Galvani
Virchow
Ciclo de Krebs
Enfermedad de Whipple
Schwann
Reaccion de Widal
Luis Galvani
Foliculo de Graaf
Asa de Henle
Aparato de Golgi
Wilhelm Conrad Roentgen
Corea de Sydenham
Tetralogia de Fallot
Billroth

\section{$\mathbf{N}^{0}$ DE BÚSQUEDAS}

68

48

30

23

21

19

18

18

17

15

12

11

10

10

10

8

8

7

6

6

6

6 
FRASE

Ganglio de Virchow

Trendelenburg

Galvanismo

Hartmann

Andres Vesalio

Triada de Charcot

Christian Doppler

Sindrome de Wallenberg

Signo de Trousseau

Síndrome de Wallenberg

Lister

Morgagni

Giovanni Battista Morgagni

Thomas Addison

Sindrome de Brown Sequard

TOTAL
$\mathbf{N}^{\mathbf{0}}$ DE BÚSQUEDAS

6
5
5
5
5
5
5
5
5
4
4
4
4
4
4
4
4

5

5

5

5

5

5

5

5

4

4

4

4

4

4

447

De todo lo dicho hasta el momento, podemos deducir que hay cierto interés por las biografías $y$, en concreto, las redactadas en castellano. No obstante, hay que señalar que algunas de las biografías que se recogen en «historiadelamedicina.org» tienen nula o escasa presencia en internet hasta el momento en cualquier idioma. Poco podemos decir del público visitante a no ser que, con el software adecuado, — que existe- pudiéramos trazar con exactitud la ruta y el origen de la visita, y aún así, no dispondríamos de suficiente información. Pensamos que no se trata de un público especializado sino, más bien, de profesionales de la medicina, estudiantes de medicina y ciencias relacionadas, así como de estudiantes de otros niveles educativos.

\section{ESPACIOS BIOGRÁFICOS EN INTERNET}

En este apartado nos referiremos a los contenidos biográficos más destacados que podemos encontrar en internet y a las herramientas que nos proporciona la propia red para localizarlos. Comenzaremos analizando cuáles son los portales, buscadores y metabuscadores más útiles para lograr nuestros objetivos. Seguiremos después con las enciclopedias y diccionarios en red, 
instrumentos que, como sus homólogos en papel, proporcionan información de tipo biográfico. Terminaremos evaluando las páginas dedicadas exclusivamente a biografías de tipo general y a biografías específicas de tipo científico o médico.

\subsection{Portales}

Se trata de espacios o sitios web que funcionan como punto de partida para navegar por Internet y que normalmente ofrecen una gran diversidad de servicios tales como listado o directorio de sitios web, buscador, noticias, e-mail, información metereológica, chat, grupos de discusión y comercio electrónico, etc. Ejemplos: Yahoo, Altavista, Terra. Entre los más destacados mencionaremos:

Sosig o Social Science Information Gateway (http://www.sosig.ac.uk/ ). Es un portal temático especializado que selecciona, evalúa, cataloga y describe con claridad los mejores recursos de internet con interés académico y científico en el campo de las ciencias sociales. Está dirigido a investigadores, profesionales y estudiantes, entre otros

Librarians' Index to the Internet o Lii.org (http://lii.org), recopilación multidisciplinar de una selección de recursos académicos.

DutchESS o Dutch Electronic Subject Service, portal temático multidisciplinar elaborado por la National Library of the Netherlands. Contiene una selección de los mejores recursos web que se distribuyen de manera gratuita por Internet, organizados por categorías: general, arte y humanidades, ciencias exactas e ingeniería y ciencias sociales (http://www.kb.nl/dutchess/nbc main.html);

BUBL Catalogue of Internet Resources, del Centre for Digital Library Research (Strathclyde University, Glasgow), portal genérico en el que puede encontrarse una selección de los mejores recursos electrónicos de interés académico y científico. Organiza los recursos, previamente seleccionados, evaluados, catalogados y descritos, por orden alfabético del título y bajo las diferentes materias y submaterias (sigue la clasificación Dewey), el alcance geográfico y el tipo de documento. Proprciona un resumen claro que describe su contenido (http://bubl.ac.uk/link/). 
The $\boldsymbol{W} \boldsymbol{W} \boldsymbol{W}$ Virtual Library (http://vlib.org/) puede considerarse como uno de los primeros portales o como un catálogo de páginas web. Fue iniciado por Tim Berners-Lee ${ }^{5}$, creador del lenguaje html y de las páginas web. Colaboran de forma desinteresada especialistas de los principales campos del saber. La información está contenida en centenares de servidores distribuidos por todo el mundo. Copias del catálogo entero se custodian en East Anglia, Argentina y Ginebra.

Wellcome Library MedHist (http://medhist.ac.uk/). Podemos considerarlo como un portal joven, con poca experiencia, dedicado a la historia de la medicina. Ofrece pocos recursos biográficos.

\subsection{Buscadores y metabuscadores}

Son aplicaciones que recorren la red localizando sitios y páginas web que hacen referencia a los términos de búsqueda que hemos introducido. Los buscadores se organizan por palabra o índices (como Lycos o Infoseek) y buscadores temáticos o directorios (como Yahoo). Dentro de estas dos categorías básicas existen muchos tipos de buscadores, con sus entornos de búsqueda o sobre determinados temas. Los metabuscadores buscan simultáneamente en varios buscadores. Entre estos podemos mencionar:

Fossick Meta Search (Web search Alliance). Metabuscador que realiza búsquedas simultáneas en buscadores internacionales aunque se puede especificar un determinado país. Permite personalizar la búsqueda así como la salida de los resultados.

http://www.fossick.com/Search.htm.

Ixquick. Metabuscador que realiza búsquedas simultáneas en una gran variedad de buscadores conocidos que varían según el idioma del formulario de búsqueda seleccionado. Tiene una interface muy sencilla.

(http://www.ixquick.com/)

Metacrawler. Se trata de un integrante de Go2Net. Potente motor de búsqueda que rastrea en las bases de datos de otros motores ofreciendo los resul-

5 Información sobre Tim Berners-Lee véase http://www.w3.org/People/Berners-Lee/ 
tados por orden de importancia. Imprescindible cuando no se sabe claramente qué buscar.

(http://www.metacrawler.com/).

ProFusion. Metabuscador con servicios propios de portal. Permite seleccionar los motores de búsqueda donde dirigir la petición

(http://www.profusion.com/default.asp?agt=0!5!)

Wisenut, searchwise, search wiser . Gran motor de búsqueda, tipo «Google», que indiza millones de páginas web y ofrece a los usuarios los resultados por orden de pertinencia y los acompaña de una selección de categorías relevantes según la búsqueda realizada.

Freeality.com (Online Biographies). Sitio no demasiado bien diseñado, pero que permite buscar personajes en algunos buscadores.

(http://www.freeality.com/biograph.htm).

Google. Se trata, quizás, del buscador más popular de Internet. Revolucionó en su día las búsquedas en este medio. Su éxito se debe a que parece saber «de forma instintiva» qué es exactamente lo que buscamos; es un motor que simplemente «funciona». Sin embargo, debajo de esa interface sencilla y limpia se esconde una herramienta con muchas posibilidades que habitualmente se desconocen. Incorpora herramientas de idioma, búsqueda en artículos de los grupos de noticias o news, barras de búsqueda, búsqueda de imágenes, etc. Permite utilizar algunos elementos de sintaxis que ayudan a la aplicación a entender qué es lo que se está buscando. Por ejemplo, podemos restringir la búsqueda a ciertos componentes de una página como el título o la URL, a ciertos tipos de páginas, como las de tipo académico, según el tipo de archivos, como documentos de texto, pdf, etc. Podemos, incluso, efectuar operaciones aritméticas. Para su uso, igual que para el del resto de motores de búsqueda, resulta útil informarse sobre las posibilidades de los mismos. Existen incluso publicaciones que nos enseñan a hacerlo ${ }^{6}$. En la búsqueda de biografías ofrece buenos resultados. Para algunos casos la experiencia nos demuestra que buscar a partir de imágenes es bastante fructífero, porque completa la busqueda ordinaria.

Por otro lado, Google ha lanzado recientemente un producto especializado en búsquedas académicas: 'Google Scholar', cuya versión beta se encuentra en

6 Véase por ejemplo CALISHain, T et al (2004 a y b) 
la dirección scholar.google.com. Alcanza un amplio espectro de materiales, desde informática a física o derecho, y emplea algoritmos especialmente diseñados para el entorno académico. Encuentra libros, artículos, documentos pdf, etc. y también proporciona la referencia de quién los cita. El servicio es gratuito $\mathrm{y}$, en principio, no llevará publicidad. En una fracción de segundo Google académico proporciona una inmensa cantidad de referencias sobre cualquier tema, con la ventaja de que se trata de referencias mucho más rigurosas que las que ofrece el buscador general. Apenas lo hemos podido utilizar porque acaba de salir - en realidad se encuentra en fase beta o de prueba-, pero parece una herramienta de gran utilidad.

\subsection{Diccionarios, enciclopedias en red}

En la red nos podemos encontrar con este tipo de obras que se corresponden con las editadas en papel a las que se añaden contenidos multimedia como imágenes, sonido, grabaciones de voz, vídeo, etc. Algunas son el complemento de la obra que se vende en CD o en papel. Buena parte son de pago $\mathrm{y}$ algunas ofrecen información muy resumida en versión free o gratuita y completa en versión de pago.

Otras veces se trata de iniciativas gratuitas y «casi experimentales» como muchas de la red en el terreno del hipertexto. Uno de los ejemplos es Wikipedia (http://en.wikipedia.org/wiki/Main_Page), una enciclopedia colaborativa en red, creada en 2001 y basada en wiki ${ }^{7}$, un software que permite a los usuarios revisar o introducir directamente los contenidos. Está traducida a cincuenta idiomas y es la única en esperanto. En poco tiempo ha cosechado dos de los premios más prestigiosos del mundo en torno a internet: Ars Electroni$c a$, en Linz (Austria) y los Webbys de San Francisco (EEUU). Como cabe suponer, los contenidos son muy desiguales y, en algunos casos, hay muchos errores. Hemos podido comprobar que, en algunos casos, los artículos son traducciones parciales - a veces mal hechas - de textos que se ofrecen en otras páginas web como las dedicadas a los premios nobel. Tiene interés como experimento y en algunos campos del saber8.

Otra iniciativa es la Encliclopedia libre Universal en Español, alojada en un servidor de la Universidad de Sevilla. Se trata de un proyecto para desarro-

7 Un wiki es una colección de páginas web enlazadas entre sí, cada una de las cuales puede ser visitada y modificada por cualquiera.

8 Véase PISAN, F. (2004) 
llar a través de Internet una enciclopedia de calidad, abierta y gratuita en español, que se convierta en una obra de referencia obligada dentro del mundo hispano, tal y como la propuso Richard Stallman en Enciclopedia Universal y Recursos de Enseñanza Libres. Buscando la calidad dispone de una serie de administradores que, a veces, establecen filtros. Entre sus más de 22.000 artículos, contiene muchas biografías; con algunas sucede lo comentado en el caso anterior. Esto hace que determinados errores se vayan arrastrando. No obstante, el cruzamiento de enlaces la hace útil para un primer acercamiento a un personaje.

\subsection{Páginas específicas sobre biografías}

Dentro de este grupo vamos a distinguir las de tipo general y las páginas dedicadas a biografías de científicos y médicos. Dentro del primer grupo nos referiremos de forma separada a las que son de tipo informativo, y las que son de pago o bien libres.

Las de tipo informativo vendrían a ser páginas intermedias entre el usuario y las páginas sobre biografías que busca. Es decir, se trata por lo general de páginas elaboradas por especialistas en un tema, por el personal de bibliotecas universitarias o virtuales, que proporcionan enlaces que apuntan a páginas que contienen estudios biográficos. Vienen a ser páginas «filtro» que pueden dar buenos resultados. Un buen ejemplo es la conocida The $W W W$ Virtual Libra$\boldsymbol{r y}$, en el apartado Information \& Libraries $>$ General References $>$ Biographical Sources. Otro ejemplo es la página sobre sitios de biografías elaborada por la Biblioteca del condado de Multnomah (http://www.multcolib.org/homework/ biohc.html), titulada Biographical Sources. An Internet Hotlist on Biographies, creada por Linda Dougherty, de la Northwest High School, o la Biographical Resources A Guide to the Collections of The New York Public Library (http://www.nypl.org/research/chss/grd/resguides/biography/)

Respecto a los sitios cuya consulta requiere suscripción, destacamos la edición en internet de World Biographical Index (Indice Biográfico Mundial). Hasta 2003 estuvo disponible sin cargo. En la actualidad se ha incluido en el World Biographical Information System Online (WBIS Online). Es, quizás, la base de datos más completa que existe, ofreciendo ya 2,28 millones de artículos biográficos digitalizados sobre 1,3 millones de personajes. Contiene, además, perfiles biográficos sobre más de 3,8 millones de personajes. Está previsto que cada año se añadan unos 2 millones de artículos biográficos. 
(www.saur.de/wbis-online). El Archivo español, portugués y latinoamericano contiene información de 152.000 personas, procedente de 333 recursos distintos publicados entre 1724 y 1963 que se han digitalizado. Se trata de una potente herramienta de gran interés aunque para ser suscrita por una biblioteca institucional.

Entre las páginas que nos proporcionan biografías destacamos:

Biographical Dictionary: Incluye más de 28.000 biografías. Puede buscarse por año de nacimiento, año de muerte, profesiones, obras y otras palabras clave.

(http://www.s9.com/biography/)

Distingued Women of Past and Present. De tipo general. Se puede buscar por tema, nombre, etc. Muy escorado hacia personajes de los Estados Unidos de América y Reino Unido. Incluye bibliografía y enlaces a otros lugares que contienen más información sobre los personajes

(http://www.distinguishedwomen.com/)

Dictionary of New Zealand Biography. Versión en línea del Dictionary of New Zealand Biography series entre 1990 y 2000, y las series en maorí, Nga Tangata Taumata Rau. Contiene unas 3.500 biografías, de las que 492 son de maoríes.

(http://www.dnzb.govt.nz/DNZB/)

Almanac: Biography. Contiene en torno a las 30.000 biografías cortas entre las que se encuentran las de bastantes científicos y médicos.

(http://www.infoplease.com/people.html)

Lives, the Biography Resource. Lugar en el que se indica que ya no se pone al día ni se añade información y que, de momento, continua disponible. Contiene biografías sólo de personas que han fallecido. Se ha desarrollado a lo largo de cinco años. Ofrece el acceso a biografías, autobiografías, cartas, diarios, historia oral, etc. Prácticamente no tiene utilidad para los historiadores de la ciencia.

http://amillionlives.com/ 
Biography.com. Contiene unas 25.000 fichas biográficas. De relativa utilidad.

(http://www.biography.com/search/index.jsp)

Anthropology Biography Web. Desarrollado por los estudiantes de la Universidad del estado de Minnesota, como parte del Emuseum. Contiene información sobre 674 antropólogos. De gran utilidad. En cada biografía se incluyen enlaces a otras páginas.

(http://www.mnsu.edu/emuseum/information/biography/index.shtml)

Vamos a referirnos, por último, a las páginas y sitios web con información biográfica de médicos y científicos.

Biography of Women Mathematicians. Desarrollada por estudiantes del Agnes Scott College, de Atlanta, Georgia. Contiene unas doscientas biografías, algunas bastante extensas, con imágenes y bibliografía. Lugar sobrio, pero interesante.

(http://www.agnesscott.edu/lriddle/women/women.htm)

Distingued Women of Past and Present (Health and Medicine. Se trata del sitio web comentado en el apartado anterior, pero lo que hace referencia a las médicas o profesionales de la salud. Casi todas las biografiadas son de Estados Unidos.

(http://www.distinguishedwomen.com/subject/health.html)

4000 years of Women in Science. Contiene más de un centenar de biografías de científicas de todas las ramas. Hay una entrada por nombres y otra por áreas científicas (http://www.astr.ua.edu/4000WS/4000WS.html)

The MacTutor History of Mathematics archive. Elaborada en la School of Mathematics and Statistics. University of St. Andrews Scotland. Contiene centenares de biografías a las que se puede acceder por nombre, por años, por actualizaciones, etc. Biografías muy completas y enlaces cruzados de todo tipo. Incluye también las referencias de los trabajos de cada biografiado. Las biografías están firmadas. (http://www-history.mcs.st-and.ac.uk/history/)

The Faces of Science: African Americans in the Sciences. Contiene un centenar de biografías de científicos de todas las ramas así como de ingenieros.

(http://www.princeton.edu/ mcbrown/display/faces.html) 
The hall of Science \& exploration. Contiene entrevistas a científicos vivos de cierta relevancia. Incluye imágenes, video y audio.

(http://www.achievement.org/autodoc/halls/sci)

Biographies of Biologists. Biosis. Contiene más de medio centenar de biografías de biólogos. (http://www.biosis.org/zrdocs/zoolinfo/biograph.htm)

The Galileo Project. Contiene un diccionario de «personajes de su tiempo» (Catalog of the Scientific Community in the 16th and 17th Centuries), con un total de 631 biografías. Permite diversos tipos de búsquedas. Ofrece una ficha de cada personaje muy estructurada. Contiene información sobre la bibliografía consultada y la no consultada. Elaborada en el Department of History and Philosophy of Science Indiana University. (http://galileo.rice.edu/)

Eric Weisstein's World of Scientific Biography. Contiene unas quinientas biografías cortas correspondientes a varias áreas científicas (astronomía, química, matemáticas y física).

(http://scienceworld.wolfram.com/biography/)

Virtual Library: Science: Chemistry: Biographies of Famous Chemists. Un lugar a tener en cuenta para la historia de la química.

(http://www.liv.ac.uk/Chemistry/Links/refbiog.html)

People and Discoveries. Este sitio ofrece unas pocas biografías de inventores y científicos.

(http://www.pbs.org/wgbh/aso/databank/bioindex.html)

Nobel e-Museum. Sitio oficial de la Fundación Nobel que ofrece la biografía de los premiados así como sus discursos de recepción del premio. En ocasiones incluye imágenes.

(http://www.nobel.se/)

Comprehensive dictionary of medical eponyms Contiene más de 6.000 biografías ligadas a sus epónimos. Algunas son amplias y otras son muy breves. El sitio puede ser de gran utilidad para un primer acercamiento. Sigue actualizándose.

(http://www.whonamedit.com/index.cfm) 
Medicine worlwide. Biografie. Sitio dedicado a la medicina. Contiene algunos temas históricos que incluyen 200 biografías, especialmente la sección Persönlichkeiten der Medizin. En alemán. Sigue actualizándose.

(http://www.medicine-worldwide.de/)

Compumedicina. Sección Historia de la medicina. Biografías de médicos de habla hispana. Elaborado por Jaime Gómez González.

(http://www.compumedicina.com/historia/hm_main.shtml)

Surgical-tutor.org.uk. Lugar dedicado a los estudiantes de medicina y a los posgraduados que preparan su especialidad. Ofrece algunas biografías de cirujanos de renombre.

(http://www.surgical-tutor.org.uk/default-home.htm?surgeon.htm right)

Biographical Database of the British Chemical Community, 1880-1970 (http://www5.open.ac.uk/Arts/chemists/) Interesante sitio web construido gracias al proyecto Studies of the British Chemical Community: the Principal Institutions, 1881-1972, dirigido por Gerrylynn K Roberts and Robin Mackie de la Open University, Reino Unido, que contiene datos biográficos de 4.100 personajes.

Historiadelamedicina.org. Página dedicada a la Historia de la Medicina. Sección «Epónimos y biografías médicas». Contiene un centenar de biografías ligadas a sus epónimos. Buena parte de ellas contiene referencias bibliográficas así como fuentes u obras del biografiado. Sigue actualizándose. (http://www.historiadelamedicina.org)

En las estrategias de búsqueda de material biográfico deben tenerse en cuenta las páginas de instituciones o centros privados, asociaciones profesionales, archivos, etc., que pueden contener secciones históricas y biográficas. En este género hemos seleccionado unas pocas:

Instituto Pasteur: Dossiers biographiques. Biografías muy estructuradas de personajes relacionados con el Instituto. Contiene también referencias a documentos de archivo así como de imágenes. Esta organizándose. (http://www.pasteur.fr/infosci/archives/f-bio.html)

The Alan Mason Chesney Medical Archives. The Johns Hopkins Medical Institutions 
(http://www.medicalarchives.jhmi.edu/index.html). Contiene información biográfica, bibliográfica así como iconográfica entre el material de archivo que custodia. De gran interés para la investigación historicomédica.

Association Internationale d'Histoire de la Psychoanalyse. (http://www. aihp-iahp.com/Main/ArchivesDocuments/index.htm) Sitio dedicado al estudio del psicoanálisis desde el punto de vista histórico. Contiene información biográfica de los creadores del psicoanálisis. La sociedad se encuentra en París.

Mayo Clinic. (http://www.mayo.edu/medlib/medlib.html). Los distintos sitios web de la institución proporcionan información sobre su historia así como de sus fundadores y médicos que han pasado por ella.

Baker-Cederberg Museum and Archives. Hospital General de Rochester. (http://www.viahealth.org/archives/historyindex.html) Sitio web que incluye mucha información de carácter histórico, entre la que se encuentran biografías de los principales médicos que han ejercido en esta institución entre 1847-1997.

Cleave's Biographical cyclopadia of homeopathic physicians and surgeons. (http://www.homeoint.org/history/cleave/) Se trata de la versión digital del texto Biographical cyclopadia of homeopathic physicians and surgeons, de Egbert Cleave (Philadelphia: Galaxy Publishing Co., 1873)

Centro de oftalmología Barraquer. (http://www.co-barraquer.es/)

Ofrece una breve biografía de la dinastía de los Barraquer. Resulta interesante para evitar errores cuando se aborda la biografía de cualquiera de ellos.

Marktbreit, Ayuntamiento. (http://www.marktbreit.de/). La casa de Alois Alzheimer. Este es el caso de un ayuntamiento de una ciudad pequeña que ha dedicado algunas páginas a Alois Alzheimer. El sitio está en alemán, inglés y español. Resulta de gran interés, especialmente lo que se refiere a la iconografía.

Museo Claude Bernard. (http://www.fond-merieux.org/musee/). Este es un ejemplo como otros tantos que pueden encontrarse en internet. Ofrece una biografía breve de Claude Bernard. Su consulta puede resultar interesante para un estudiante de medicina. 
Las TIC también han facilitado la consulta de artículos de revistas especializadas. Especialmente provechosa resulta la búsqueda de biografías en las revistas médicas. Una búsqueda en MEDLINE (PubMed: http://www.ncbi. nlm.nih.gov/entrez/query ) de un personaje arroja de inmediato las referencias de algunos artículos que podemos consultar a continuación. Lamentablemente, para una mayoría de revistas es necesario estar suscrito. Las instituciones recurren cada vez más a las suscripciones de revistas con edición digital. De todas formas, muchas ofrecen la posibilidad de obtener una copia en $p d f$ previo pago del coste del servicio. Por otra parte, muchas revistas importantes han acometido la labor de digitalizar sus fondos anteriores a las ediciones digitales, lo que, sin duda, todavía facilitará más el trabajo de investigación.

\section{CONCLUSIONES}

A través de este trabajo hemos pretendido mostrar las posibilidades que ofrecen las TIC para el trabajo de tipo biográfico. Es imprescindible no confundir este tipo de tecnologías con lo que son algunas de sus posibilidades, como internet. En estos momentos las TIC están sustituyendo los sistemas tradicionales de gestión por otros completamente renovados, lo que influye, por ejemplo, en la concepción y ejecución de proyectos de investigación.

También hemos podido comprobar cómo las biografías científicas y médicas - un aspecto de nuestra área de trabajo - interesan a un público amplísimo que incluye sectores a los que no habíamos llegado hasta ahora y que están dispersos por todo el planeta. Esta realidad está más asumida por los que buscan conocimientos que por los que los producen. Está claro que, a la hora de difundir o divulgar nuestros trabajos no se pueden dejar de lado las oportunidades que nos ofrecen estas tecnologías. Tampoco hay que olvidar que este tipo de difusión lleva aparejada una nueva forma de comunicar que tiene sus propias pecualiaridades. No se pueden despreciar las posibilidades que ofrecen, entre ellas las de integrar distintos tipos de información como texto, audio y vídeo o crear itinerarios no lineales o jerárquicos.

Por último, debemos señalar que las TIC en sí mismas así como los contenidos biográficos disponibles en internet no son una panacea, pero a nadie se le ocurre ponerse a trabajar en un determinado tema sin recurrir a estos medios y herramientas. Como hemos visto, en una buena parte de las ocasiones nos podemos encontrar con materiales que no desvelan sus fuentes, no aportan bibliografía o referencias y carecen de rigor. Otras veces se trata de la mera transcripción de trabajos que están publicados en otros soportes o con- 
tienen gravísimos errores. Apenas se encuentran algunos casos de biografías concebidos para internet y con textos redactados de forma científica.

\section{BIBLIOGRAFÍA}

BoIsot, M. (2004), «Conocimiento y gestión», Papeles de infonomía, 27 (Septiembre), 24-27.

Bosco, R.; CALdANA, S. (2004), «Wikipedia gana en Ars Electronica y en los Webbys». El País, 20-05-2004.

Calishain, T.; DoRnfest, R.; ADAMS, D.J. (2004a), Google. Guía de bolsillo. Madrid, Nowtilus

Calishain, T.; Dornfest, R.; AdAMs, D.J. (2004b), Google. Los mejores trucos. Madrid, Anaya.

CORNELlÀ, A. (2003), «Las tecnologías de la información ya no son estratégicas: son sólo infraestructura». Papeples de Infonomía, 15 (Julio-Agosto), 3-7.

GREGSON, K.(2004), Virtual Communities: Bibliography and Resource Guide. Department of Telecommunications, Indiana University. http://www.ithaca.edu/faculty/ kgregson/virtual_communities.html

KoоTAK, C.P. (2003), Espejo para la humanidad. Introducción a la Antropología cultural. $3^{\mathrm{a}}$ ed., Madrid, Mc Graw Hill.

Michaelson, K. (1996), Information, Community, and Access. Social Science Computing Review, 14(1): 57-59.

PISAN, F. (2004), La gran aventura de la «wikipedia». El País, 05-02-2004.

QUE DEVELOPMENT GROUP (1995), La biblia de internet. Madrid, Anaya.

VEÀ, A. (2004), «Andreu Veà entrevista a Tim Berners-Lee, director del WWW Consortium W3C e inventor del Web». Papeles de Infonomía, 21 (Febrero), 2730 y 22 (Marzo), 30-34. 